\title{
Review: selective serotonin reuptake inhibitors differ from tricyclic antidepressants in adverse events
}

Trindade E, Menon D. Selective serotonin reuptake inhibitors (SSRIs) for major depression.Part I. Evaluation of the clinical
literature. Ottawa (ON): Canadian Coordinating Office for Health Technology Assessment, 1997 Aug. Report $3 E$.

\section{Objective}

To compare the efficacy, completion rates, and adverse event rates of selective serotonin reuptake inhibitors (SSRIs) with tricyclic antidepressants (TCAs) in treating depression.

\section{Data sources}

Studies were identified by searching Medline, Embase, PsycINFO, International Pharmaceutical Abstracts, Pascal, Health Planning \& Administration, Mental Health Abstracts, PharmacoEconomics \& Outcomes News, and Current Contents databases (1980 to May 1996); scanning bibliographies of retrieved articles; hand searching journals; and consulting researchers.

\section{Study selection}

Studies were selected if they were double blind, randomised controlled trials, used antidepressant treatment for 4-12 weeks, and reported numerical or graphical data. Studies were excluded if they reanalysed data from previous studies.

\section{Data extraction}

Data were extracted on efficacy, study completion, and adverse events.

\begin{abstract}
Main results
162 randomised controlled trials were reviewed. SSRIs and TCAs were equally effective and the study completion rates did not differ. 7 adverse events increased and 3 decreased for SSRIs compared with TCAs (table). There were no differences in palpitations, urinary disturbance, fatigue, tremor, hypotension, \{blurred vision, anorexia, and sweating\}*.
\end{abstract}

\section{Conclusions}

Serotonin selective reuptake inhibitors do not differ from tricyclic antidepressants in efficacy or completion rates, but have different adverse events: more nausea, diarrhoea, anxiety, agitation, insomnia, nervousness, and headache, and less dry mouth, constipation, and dizziness.

* Calculated from data in article.

Sources of funding: Federal, Provincial, and Territorial Governments of Canada.

For article reprint: $\mathrm{Dr}$ E Trindade, 110-955 Green Valley Crescent, Ottawa, Ontario K2C 3V4, Canada. Fax +16132265392 .

Abstract and commentary also published in Evidence-Based Medicine 1998 May-Jun.

Selective serotonin reuptake inhibitors (SSRI) v tricyclic antidepressants (TCA)*

\begin{tabular}{|c|c|c|c|c|c|}
\hline Outcomes & SSRI weighted EER & TCA weighted CER & $\operatorname{RRR}(95 \% C I)$ & Weighted ARR & $N N T(C I)$ \\
\hline $\begin{array}{l}\text { Dry mouth } \\
\text { Constipation } \\
\text { Dizziness }\end{array}$ & $\begin{array}{l}21 \% \\
10 \% \\
13 \%\end{array}$ & $\begin{array}{l}55 \% \\
22 \% \\
23 \%\end{array}$ & $\begin{array}{l}61 \%(54 \text { to } 66) \\
46 \%(33 \text { to } 56) \\
45 \%(30 \text { to } 56)\end{array}$ & $\begin{array}{l}34 \% \\
12 \% \\
10 \%\end{array}$ & $\begin{array}{l}3(3 \text { to } 4) \\
9(7 \text { to } 13) \\
10(8 \text { to } 16)\end{array}$ \\
\hline Outcomes & SSRI weighted EER & TCA weighted CER & $R R I(C I)$ & Weighted ARI & $N N H(C I)$ \\
\hline $\begin{array}{l}\text { Nausea } \\
\text { Diarrhoea } \\
\text { Anxiety } \\
\text { Agitation } \\
\text { Insomnia } \\
\text { Nervousness } \\
\text { Headache }\end{array}$ & $\begin{array}{l}22 \% \\
13 \% \\
13 \% \\
14 \% \\
12 \% \\
15 \% \\
17 \%\end{array}$ & $\begin{array}{l}12 \% \\
5 \% \\
7 \% \\
8 \% \\
7 \% \\
11 \% \\
14 \%\end{array}$ & $\begin{array}{l}83 \%(53 \text { to } 119) \\
130 \%(17 \text { to } 355) \\
77 \%(18 \text { to } 165) \\
66 \%(-6 \text { to } 195) \\
60 \%(25 \text { to } 105) \\
44 \%(9 \text { to } 91) \\
31 \%(12 \text { to } 53)\end{array}$ & $\begin{array}{l}10 \% \\
8 \% \\
6 \% \\
6 \% \\
5 \% \\
4 \% \\
3 \%\end{array}$ & $\begin{array}{l}11(8 \text { to } 15) \\
13(8 \text { to } 59) \\
16(10 \text { to } 53) \\
19(10 \text { to } 437) \\
22(15 \text { to } 46) \\
29(17 \text { to } 99) \\
33(19 \text { to } 127)\end{array}$ \\
\hline
\end{tabular}

*Abbreviations defined in glossary; RRR, RRI, ARR, ARI, NNT, NNH, and CI calculated from data in article.

\section{Commentary}

Choosing whether to use a tricyclic or SSRI as first line treatment of depression remains a controversial problem despite many trials and meta-analyses. This detailed systematic review by the Canadian Coordinating Office for Health Technology Assessment (CCOHTA) examines the issue in more depth than most of its predecessors and reaches conclusions which agree with much (but not all) previous work. What is new is the exploration of dosage of tricyclics and side effects.

There has long been a consensus that tricyclics are only effective in doses $>100$ $\mathrm{mg}$ of amitriptyline or equivalent. ${ }^{1}$ Despite this consensus, there is considerable evidence that general practitioners treat depression with low dose tricyclics. One strong argument in favour of SSRIs is the relative ease with which therapeutic doses may be attained. However, this review shows that even when standard SSRIs doses are compared with low dose tricyclics there is no difference in efficacy. This is less surprising than it may seem; the evidence that high doses of tricyclics are required is flimsy and based on a handful of small trials.

SSRIs are pharmacologically "cleaner" and therefore, we are often told, have fewer side effects. This is the first systematic review to assess the frequency of side effects and unsurprisingly shows that patients on SSRIs report nausea and anxiety, whereas those on tricyclics complain of constipation and dry mouth. SSRIs were associated with a greater total number of side effects than tricyclics: a finding which may have many interpretations but runs counter to most promotional literature. Which drug is better tolerated? This question is usually answered by using the proxy measure of dropout rates from trials, and this review found similar dropout rates for both treatments except in adult outpatients who were more likely to drop out on tricyclics.

(continued on page 51) 